083.

\section{Some Features of Organizing Medical Services to Victims of Burns in Underground Settings}

E.M. Altshuler, I.K. Galeev, A.V. Salskiy

Emergency Medical Center, Regional Burn Center,

Kemerovo, Russia

Explosions of coal dust and methane in underground workings very often are accompanied by terminal injuries of miners skin. As a rule, there are many victims having extensive and deep burns and very often respiratory tract involvement.

The Kemerovo Burn Center and Regional Center of Emergency Medicine has been involved with the treatment of victims of two explosions in mines. There were 22 persons involved. As the fire was of short duration, the burns appeared on opened parts of body: face, upper extremities, and trunk. None of the victims suffered lung barotrauma, but all had inhalation of the products of combustion. Most of them could move without assistance and were able to get out of the mine.

It's very important to start the infusion therapy for burn shock early. In all of our cases, infusion therapy was carried-out through peripheral veins by fighters of Military Rescuing Mining Department. The skin was covered with considerable coal dust that made the diagnosis of the area and depth of burn very difficult. In addition, there were some cases of burn shock.

The victims were transported immediately to the nearest medical institution where the anti-shock therapy was continued by members of the combustiological brigade of the Regional Medical Emergency Center. Such tactics are required by the impossibility of immediate smooth transportation of the victims to the Regional Burn Center because of the remoteness of the accident site. The long time required for transportation renders the burn disease more complicated and resulted in the early onset of renal failure. Within 3 to 4 days of the incident, the victims were transferred by helicopter to the Regional Burn Center where they were given special help (necrectomy, active detoxification, hyperbaric oxygenation, intravenous laser therapy, and skin restitution). Three ( $14 \%$ ) of 22 died, their index of heaviness was from 180 to 220 , and they had infection of respiratory tract. The principle cause of death was burn toxemia with multiorgan failure.

Thus, this experience speaks to the inexpediency of long distance transportation of burn patients following an accidents in the mines, and affirms the necessity the organizing specialized teams in a Regional Emergency Medical Center.

\section{2.}

\section{Multifactor and Combined Traumas in Fire Victims}

\section{O. Dmitrienko}

St. Petersburg Medical Academy of Postgraduate Studies, St. Petersburg, Russia

The characteristics of fire victims were evaluated taking into consideration the city demographic indices. A model contingent of victims similar to that with clinically analogous traumas acquired in extreme situations was selected. They were high risk patients. It is this pathology that is the most difficult factor to be considered in organizing medical assistance to fire victims and in their treatment.

The indices of trauma severity, the course, and the outcome of 1,049 victims were studied (293 patients with deep burns involving over 10\% BSA; 491 with similar condition plus inhalation trauma; 107 with thermo-mechanical trauma; 61 pregnant women; and 97 who died in fires). Every trauma taken separately is well-known to specialists. Even though combined tramas are rare for burn victims, they practically are constant for fire victims. Hence, multiple severe organic changes in organism also are typical. The result is the multifactor character of clinical manifestations: a mixed clinical picture with integration of thermal, mechanical, and inhalation traumas. The fire victim's pathology noticeably is influenced by the patients "background" (i.e., the state before trauma).

The results of our study indicate that such factors as past diseases in adults and children, advanced age, pregnancy, and psychogenic illness after-effects are not significant factors.

The results confirm the historically formed concept that the "fire victim" in particular has the most severe form of burn trauma, and the concept of "fire victim's pathology" is necessary for medical specialists and for those involved in assistance to fire victims.

\section{6. \\ Psycho-Social Rehabilitation in Sarajevo: Impacting the Infrastructure}

D.L. Creson, $M D, P h D$

University of Texas-Houston Health Science, Houston, Texas USA and CRS, Sarajevo, Bosnia

This paper describes data collected during the first six months of a project designed to develop and support staff of four social service centers serving specific catchment areas in Sarajevo, Bosnia and paraprofessionals working in refugee centers in that city. The project was developed, implemented, and sustained while the city was under siege. The social service centers and refugee centers are on the lowest rung in the mental and social health system of the city. As a consequence, they receive the least support to from governmental and non-governmental aid agencies. Staff members working in the social service and refugee centers have been subject to the same severe and continuous trauma as the clients they serve. Working conditions, particularly during the frigid winter and during periods of intense shelling, are extremely poor. For this reason, these settings seemed ideal for rigorous testing of the hypothesis that collaboration of expatriates and locals can have substantial positive consequences.

This paper presents and discusses the observed consequences of this project in relation to three phases: development, implementation, and outcome. Social obstacles and dysfunctional preconceptions that impede programmatic goals are identified and discussed as are synchronistic cultural variables that unexpectedly facilitate progress toward stated objectives. Finally, a brief working paradigm for the development of psychosocial 